\title{
SBFPO, Trinta anos de História
}

\author{
LUIZ CARLOS LOPES ${ }^{(1)}$
}

Rapidamente, trinta anos se passaram desde a fundação da Sociedade Brasileira de Floricultura e Plantas Ornamentais SBFPO. Grandes mudanças aconteceram no país e no mundo, especialmente nos meios de comunicação. Assim, também a nossa sociedade científica evoluiu e mudou; mudou para melhor, favorecendo também mudanças vitais para aqueles que lidam com Floricultura e Plantas Ornamentais, em especial no âmbito do ensino e da pesquisa. Hoje, a realidade é bastante diferente de trinta anos atrás; apesar de ainda haver alguma deficiência, a oferta de informações, cursos, literatura e material é muito maior, e as pessoas inseridas nesse contexto não têm consciência das dificuldades e dos preconceitos enfrentados, nas instituições oficiais, por aqueles que cresceram antes da era da Internet para se ensinar, pesquisar, ou mesmo trabalhar nessa área. Hoje, não se imagina qualquer trabalho sem o computador e a Internet, dupla que também tem seu lado perigoso, podendo levar à preguiça mental, adoção de idéias, trabalhos e conclusões de outros. Muitos não querem realizar, eles mesmos, suas pesquisas bibliográficas, lendo artigos, consultando livros, comparando situações e resultados, limitando, então, seus conhecimentos. Chega-se ao extremo de buscar receber tudo pronto pela Internet. É pena!

Tendo lecionado, vivido e trabalhado no meio acadêmico nesses dois momentos da história, me atrevo a um pequeno retrospecto, que evidencia a importante presença e ação da SBFPO.

A história do ensino e do trabalho científico sistematizado na área de floricultura, plantas ornamentais e paisagismo no Brasil, carece ainda de muitas informações. Aqui, pela Zona da Mata das Minas Gerais, especificamente na UFV - Universidade Federal de Viçosa -, onde nasceu a SBFPO, fornecemos breve relato. Sabe-se que na ESAV - Escola Superior de Agricultura e Veterinária de Viçosa -, criada em 6 de setembro de 1920, ao mesmo tempo em que se realizavam as obras de infra-estrutura para sua implementação, procedia-se também à organização das coleções de plantas que comporiam o acervo inicial e básico para o ensino e a pesquisa da instituição. Em 1926, foi criado o "Boletim de Imprensa", com o objetivo de informar sobre a instituição, bem como difundir recomendações básicas sobre Cultivo de Plantas e Veterinária aos cidadãos em geral, a diversos estabelecimentos e aos principais jornais do estado. Dentre os primeiros dezesseis números editados, um deles foi em floricultura, sobre Amaryllis. Em 1927, ainda antes de se iniciarem os cursos regulares, foi realizada a primeira exposição de Citrus e Dálias. Ante a boa adaptação das dálias às condições locais, já se aventava a hipótese de se estimular seu cultivo para venda, como flores cortadas, para o mercado do Rio de Janeiro.

Na década de 30, havia a disciplina de Jardinagem. Por motivos não bem esclarecidos, talvez a preocupação excessiva de concentrar recursos humanos, financeiros e materiais na produção de alimentos, o ensino e os trabalhos nessa área diminuíram, a ponto de, no final dos anos $50 / 60$ s, esse conteúdo ser apenas parte da disciplina Olericultura e Jardinocultura, na qual breves noções eram ministradas, nas últimas aulas. Além disso, a literatura disponível representava grande entrave. As bibliotecas mais bem aquinhoadas e com mais acervo possuíam obras em Inglês ou Francês: livros, periódicos e boletins técnicos - estes até bastante variados - que abordavam condições e espécies de plantas, então, diferentes das cultivadas no Brasil. Em Português, a revista mais difundida era "Chácaras e Quintais", de cunho prático; havia também alguns artigos de jornais, a maior parte sobre árvores ornamentais, escritos pelo Engenheiro Agrônomo Hermes Moreira de Souza, do Instituto Agronômico de Campinas - IAC -, além de alguns boletins. Assim, o ensino era bastante precário, quase nulo.

Em 1964, assumi o setor de Jardinocultura na Escola Superior de Agricultura - ESA (antiga ESAV) - e logo fui tachado de 'florzinha'. Em levantamento realizado em 1965/6, além da ESA, somente a ESALQ informou ministrar ensinamentos na área, apesar de também não ter professores com treinamento adequado. Portanto, nem se sonhava com bom ensino e, muito menos, com pesquisa.

Em contraposição ao atraso do ensino e da pesquisa, muitos horticultores, despertos para o promissor campo da floricultura, ainda nos anos 50s, buscaram, no exterior, técnicas de cultivo e matrizes de plantas, especialmente para o corte de flores. Entre fracassos e acertos, foi criada a produção comercial de flores cortadas, em especial pelos associados da Cooperativa Agrícola de Cotia e Holambra e, mais tarde, também pelos da UNIFLOR.

Apesar das reformas curriculares implementadas até 1970, não se admitia a disciplina de floricultura e plantas ornamentais no currículo de agronomia. Na ESA, apenas se conseguiu expandir a disciplina de jardinocultura, o que não aconteceu na maior parte das escolas do Brasil, muitas alegando falta de recursos humanos, financeiros e bibliográficos. Diante dessa realidade, era preciso agir na motivação e preparação dos professores. A oportunidade era boa, uma vez que os programas pioneiros de pós-graduação atraíam grande número de professores, de todos os estados do Brasil. Pela pós-graduação, poderse-ia chegar às instituições de ensino.

Tendo concluído meu Mestrado em Floricultura - o primeiro no Brasil - e devido ao fato de a UFV (antiga UREMG) já dispor de uma boa e ativa floricultura, criamos a disciplina de Floricultura na pós-graduação. Nesse curso, dava-se ênfase ao controle de crescimento e floração de plantas, sistemas de produção e pós-colheita. Era optativa para os inscritos na área de produção vegetal. Vale notar, contudo, que atraiu mais alunos do que se previa, e todos que a cursaram se dispuseram a lutar pela inclusão dessa área de estudos e pesquisa em suas instituições. Algumas dessas, não impediam que algum interes-

(1)PHD, Professor titular aposentado UFV 
sado fizesse observações na área, apesar de não terem em seus quadros, técnicos especializados em floricultura e ornamentais, especialmente no âmbito fitossanitário.

Outro grande entrave era o isolamento das instituições. Havia dificuldade de comunicação, corria-se o risco de extravio de correspondência, a entrega levava vários dias, e até o contato telefônico era demorado. Tornava-se imperiosa a necessidade da criação de um grupo de trabalho, ou mesmo um foro de discussões, para se pressionar as instituições de ensino e pesquisa a se envolverem com floricultura, plantas ornamentais e paisagismo. Nesse momento, os técnicos extensionistas enfrentavam inúmeras questões dos produtores de flores e plantas, sem conseguir fornecer orientação segura.

Para se publicar um trabalho científico, em qualquer área do conhecimento agronômico, o único veículo era a revista oficial ou os anais das instituições. Por vezes, dado o número de trabalhos na fila, havia demora de mais de ano para a publicação. Além disso, outra questão importante era o fato de esses periódicos serem catalogados pelas bibliotecas que os recebiam em Assuntos Gerais, pois, no mesmo número, eram publicados assuntos de diversas áreas do conhecimento. Por isso, eram pouco consultados, especialmente no exterior.

As deficiências do ensino e da pesquisa não impediram que, em 1970, a produção comercial, e até a exportação de flores, crescessem. Porém, a elevados custos, por estarem apoiadas tanto em técnicos como em sistemas e técnicas estrangeiros, nem sempre adequados ao país. Assim, tornava-se clara a necessidade de se abrir uma frente para promover o ensino e a pesquisa em floricultura e plantas ornamentais.

Em São Paulo, nos anos 60s, havia a Sociedade Brasileira de Floricultura - SBF - à qual me associei. Essa promovia exposições e cursos rápidos em floricultura e plantas ornamentais, chegando até a editar alguns números da revista "Flores do Brasil". Dirigida pelo dedicado e idealista casal de Engenheiros Agrônomos, Nilva de Oliveira Fialho e João Fialho, do Instituto de Botânica de São Paulo, era voltada para a população paulistana. A maioria dos sócios eram senhoras da alta sociedade, embora também admitisse crianças, os chamados 'sócios mirins'. A SBF, embora reconhecida como de 'utilidade pública', ao final daquela década, com menos de 5\% dos associados em dia com a tesouraria, tornou-se inadimplente e inviável de ser transformada em sociedade científica, conforme se buscava.

Durante dois congressos - 1970 e 1976 -, a Sociedade de Olericultura do Brasil (SOB), recusou o pedido de se abrir espaço para uma seção de Floricultura. Tornava-se, pois, necessária, a criação de uma sociedade científica, específica nessa área.

Essa iniciativa recebeu o apoio dos Engenheiros Agrônomos Heloisa Mattana Saturnino - Pesquisadora da EPAMIG - Hildebrando Lopes dos Santos - Coordenador Regional de Horticultura da EMATER - Juiz de Fora, MG - e Luiz Gomes Correia - Coordenador Geral de Horticultura da EMATER -, os quais decidiram promover um encontro que envolvesse professores, pesquisadores, extensionistas e também produtores de flores e plantas ornamentais. Para se obter o apoio institucional na promoção de tal evento, era preciso contar com um grupo de profissionais e trabalhos que pudessem ser apresentados, justificando, assim, sua realização. Três anos foram necessários para tal. Finalmente, foi divulgada a convocação para o período de 15 a 18 de fevereiro de 1979, na UFV. Adiado às vésperas, ante as intempéries que isolaram Viçosa, foi finalmente realizado de 3 a 6 de julho daquele ano. Assim, foi realizado o $1^{\circ}$ Encontro de Pesquisadores em Floricultura e Plantas Ornamentais, com a presença de 40 técnicos e 6 produtores, de diferentes instituições e lugares do Brasil. E, no dia 5 de julho, às $22 \mathrm{~h}$, foi lida e aprovada a ata de fundação da sonhada, desejada e necessária Sociedade Brasileira de Floricultura e Plantas Ornamentais.

Durante o encontro, foi possível reconhecer que realmente era o momento de se tomar tal iniciativa, e os benefícios advindos seriam inúmeros. Foi um encontro de alegria e entusiasmo, pois pela primeira vez, no Brasil, um grupo de pessoas se reunia, com grande dedicação e interesse pela Floricultura. Por três dias, falou-se de Floricultura, relatando-se a situação nas diferentes instituições, bem como em cada estado.

O sonho da floricultura começava a se tornar realidade para o ensino e para a pesquisa. Estava criada a base de apoio, um elo entre aqueles que sonhavam com uma floricultura forte, dinâmica, ensinada, pesquisada e promovida, em paridade com as outras áreas do conhecimento agronômico. A partir daquele momento, o pleito para a inclusão dessa área de atividades em várias instâncias do governo, Universidades, órgãos de Pesquisa e Extensão, passava a ser mais respeitado, em nome de uma Sociedade organizada e legalmente constituída.

A cada congresso realizado, a Floricultura era colocada em destaque em todos os órgãos de imprensa. Isso corroborou para abrir os olhos de muitos dirigentes que, ainda ciosos e tímidos em dividir seus espaços e recursos, humanos e materiais, passaram a admitir a importância dessa área como empregadora de mão de obra, geradora de recursos e qualidade de vida, deixando, assim, de rejeitá-la por 'não ser produtora de alimentos', conforme muito se ouvia até então.

Nos congressos nacionais, realizados periodicamente, é promovida a salutar e proveitosa troca de informações entre aqueles que realizam a pesquisa científica, a aplicada, os professores que as utilizam em suas disciplinas e os extensionistas que são, em especial, os intermediadores entre ensino, pesquisa e produtor. A presença do produtor num congresso científico é importante para que interaja com os pesquisadores e, pessoalmente, relate suas experiências, dificuldades, seus acertos, levando à abertura de novas frentes (linhas) de pesquisa. Por outro lado, faz com que ele também se conscientize da necessidade de pesquisa e do risco de se introduzirem práticas não aprovadas pela pesquisa, aventurando-se a inovar.

Outro benefício da SBFPO, diz respeito à possibilidade de publicação, em periódico próprio, de trabalhos científicos, apresentados ou não em congressos, em anais ou em revista especializada, o que aumenta consideravelmente sua difusão entre os técnicos da área, atribuindo-lhes mais crédito e favorecendo o intercâmbio entre congêneres.

Os congressos nacionais estimulam a realização dos certames regionais, ou locais, que já se multiplicam, abrindo espaço para cursos, palestras, exposições e concursos, despertando, assim, a atenção de um novo contingente de pessoas e instituições, até então distantes ou indiferentes àquela atividade.

Parabéns Sociedade Brasileira de Floricultura e Plantas Ornamentais! 